\title{
Há evidências da discussão da dialética na administração pública brasileira?
}

\section{Are there evidence of the discussion of dialectics in Brazilian Public Administration?}

Wesley de Almeida Mendes - Doutor em Administração, pelo Programa de Pós-Graduação em Administração da Universidade Federal de Viçosa (UFV). E-mail: wesleyadm@live.com

Clarice Pereira de Paiva Ribeiro - Doutoranda em Administração, pelo Programa de Pós-Graduação em Administração da Universidade Federal de Viçosa (UFV). E-mail: claorion@gmail.com

\section{Resumo}

A dialética é uma concepção da realidade, por vezes tratada como método ou como a própria representação da realidade, que surgiu na Grécia antiga, e posteriormente retomada por Hegel e Marx. Nesse sentido, o presente estudo tem por objetivo relatar se há a discussão do movimento dialético dentro do campo de estudos da administração, em particular da administração pública. Foram analisados 45 artigos do periódico O\&S e no portal Spell publicados entre 2014 e 2019 que contemplavam a palavra dialética. Os artigos foram analisados conforme categorias prévias de análise, considerando para estas categorias, as concepções dialéticas hegelianas e marxistas. Como resultados encontra-se diferentes aplicações da visão dialética, considerando a contradição, dialética como movimento entre outras. Nota-se ainda predominância do materialismo nos estudos de administração.

\section{Palavra-chave}

Movimento Dialético. Dialética Hegeliana. Dialética Marxista. Administração Pública.

\begin{abstract}
Dialectics is a conception of reality, sometimes treated as a method or as the very representation of reality, which emerged in ancient Greece, and later taken up by Hegel and Marx. In this sense, the present study has as objective to report how the dialectical movement presents itself within the field of studies of the administration, in particular of the public administration. We analyzed 45 articles of the O\&S periodical and Spell portal published between 2014 and 2019 that contemplated the dialectical word. The articles were analyzed according to previous categories of analysis, considering for these categories the Hegelian and Marxist dialectical conceptions. As results we find different applications of the dialectical view, considering the contradiction, dialectic as movement among others. Note also the predominance of materialism in the administration studies.
\end{abstract}

\section{Keywords}

Dialectical Movement. Hegelian Dialectic. Marxist Dialectics. Public Administration. 


\section{INTRODUÇÃO}

A concepção da dialética como "método" para se buscar a verdade e sua utilização não é prerrogativa dos séculos atuais, mas consiste em um movimento oriundo da filosofia grega, em que se destacam as influências de Heráclito, Parmênides, Zênon, Sócrates e Aristóteles. Contudo, apesar da influência clássica, o método dialético baseado na tríade: tese/antítese/síntese foi desenvolvido por Fitche, e as discussões sobre a dialética, considerando-a como um sistema, foram retomadas por Hegel e, mais tarde, por Marx. Estes contribuíram para salientar a importância da dialética no campo filosófico para entendimento da realidade.

Embora Marx e Hegel apresentem divergências na concepção da dialética, ambos observam o movimento dialético pela contradição de elementos. Para Hegel, tais contradições são concebidas pelo idealismo, cujos elementos se desenvolvem na consciência do filósofo. Marx, por sua vez, trabalha este movimento da contradição pela própria concretude desses elementos.

Para Hegel (1974), a dialética não trata de um método, mas a própria representação da realidade, sendo essa como o filósofo observa o mundo, o que torna a realidade diferente para cada indivíduo.

Apesar desses destaques quanto à representação hegeliana para a dialética, ao considerar a dialética como um movimento, e que este movimento é do real, e que este real é dialético, essa análise é observada em diversos campos, como nas filosofias do Estado e do Direito. Além disso, Marx, ao criticar a visão hegeliana, trata a dialética como algo concreto e suas observações possuem relevância nos campos social, político e econômico.

Neste sentido, nota-se que o movimento dialético, das contradições e de embate de ideias e de objetos é trabalhado em diversas áreas, considerando as relações sociais, da formação do Estado, entre outras.

A administração pública, assim, é um importante campo para observação do movimento dialético, uma vez que é uma área que envolve os elementos sociais, políticos e econômicos, que exigem diferentes habilidades dos gestores, sendo importante conciliar diversas ações, entre elas as políticas e administrativas, e que muitos conflitos surgem durante este processo, considerando as necessidades e desejos sociais, as estratégias da gestão e de fatores externos, entre as quais a economia internacional, relações institucionais e questões ambientais.

Esses conflitos gerados dentro da administração pública podem ser tratados sobre diversas perspectivas, mas devido às suas características e às finalidades da área gerencial, seus estudos possuem maior concentração no meio funcionalista. Contudo, não se deve descartar o interesse e a importância da 
compreensão do movimento dialético na administração pública, uma vez que para a gestão pública atender aos anseios sociais, devem-se colocar em evidência os seus elementos conflituosos.

Neste sentido, o presente estudo tem por objetivo relatar se há discussão do movimento dialético dentro do campo de estudos da administração pública. Este estudo, assim, se justifica por tentar apresentar como se encontram as pesquisas que discutem a dialética no âmbito da administração pública, considerando, para tanto, os conceitos tratados por Hegel e Marx na construção de suas concepções sobre o movimento dialético.

O estudo está estruturado da seguinte forma, além desta introdução, a seção seguinte busca uma contextualização sobre o movimento dialético, expondo os principais autores e obras, o conceito de dialética e sua verificação como um movimento e não como uma metodologia. Posteriormente o estudo discute a dialética sobre a visão hegeliana e marxista, suas características e críticas. Em seguida, discute os procedimentos metodológicos que foram utilizados para composição do artigo. Na seção 5 , os achados preliminares nos portais de buscas realizadas. Em seguida busca verificar nos artigos encontrados, como discutem ou apresentam a dialética e, em seguida, como a dialética é tratada nos estudos da administração considerando as categorias prévias de análises, construídas a partir dos principais conceitos e características hegeliana e marxista. Por fim, são apresentadas as considerações finais que podem ser extraídas a partir das análises desses estudos e do movimento dialético.

\section{PRECURSORES DO MOVIMENTO DIALÉTICO}

Para compreender a ideia do movimento dialético torna-se importante uma contextualização e uma análise de sua origem, de seus precursores e seu significado. Para tanto, o presente tópico visa resgatar este componente histórico sobre a dialética com vistas a lançar luz sobre o ponto onde se encontram as discussões dialéticas no meio acadêmico da administração pública.

Para Abbagnano (2007), pode-se extrair da dialética quatro conceituações, uma para cada corrente: para Platão, trata-se do método de divisão; para Aristóteles, a dialética é a lógica do provável; os estoicos consideram o termo como lógica, enquanto para Hegel é a síntese dos opostos.

O pensamento dialético inicia-se na Antiguidade, com início ainda não consensual, mas remonta do período pré-socrático, com pequenos fragmentos dos relatos de Heráclito e, posteriormente de Platão e Aristóteles (NASCIMENTO JÚNIOR, 2000). Contudo, o tema ficou por muito tempo sem grandes avanços, 
e só retomou com maior força mais de dois mil anos mais tarde, com os escritos de Hegel e, logo em seguida, sobre a perspectiva de Marx, como confronto às ideias hegelianas.

Platão considerava que o caminho para conhecer a verdade necessitava da desvinculação das concepções prévias, das crenças e opiniões, sendo importante o uso de um diálogo racional para este exercício (CHAUÍ, 2000). O confronto de ideias contrárias realizadas entre os filósofos no momento destes diálogos, para Platão, foi denominado Dialética (CHAUÍ, 2000).

Segundo Chauí (2000, p. 230), a dialética platônica consiste em "uma atividade intelectual destinada a trabalhar contrários e contradições para separálos, chegando à identidade da essência ou da ideia imutável".

Aristóteles, por sua vez, critica a forma como a diaresis é empregada, a indiferença entre o contrário e o contraditório dentro de uma sistemática de argumentos filosóficos (GIANNOT'TI, 2008). A crítica de Aristóteles dirigia-se ainda sobre o modelo dedutivo que a dialética era proposta e, para descrever a realidade, era necessário que o silogismo, conjunto de proposições construídas para obter uma conclusão verdadeira, deveria passar pelo método indutivo, que seria um resultado alcançado pelo conhecimento (CHAUÍ, 2000).

Mais de dois mil anos depois, Hegel assume uma posição própria para a dialética. Em suas percepções, parte da diferença entre a analítica e dialética proposta por Aristóteles, mas concebe como base a dialética platônica para compor sua filosofia (GADAMER, 2012).

Hegel, contudo, conhecendo da filosofia antiga, considera a dialética de Parmênides e de Platão "como a mais perfeita obra de arte da dialética antiga" (HEGEL, 1974, p. 44). Os filósofos românticos, por sua vez, não aceitavam tal divisão, mas, segundo Hegel, suas soluções não juntaram esses pontos e, ao invés do apoio sobre o Sujeito, como proposto por Kant, se voltaram para a Natureza (HEGEL, 2016).

Assim, para solucionar essa separação do sujeito e da natureza, Hegel não nega a visão de Kant quando fala que a mente determina a realidade, bem como que a racionalidade é o real e a realidade é racional (HEGEL, 2016).

Entre as obras em que Hegel constrói seu sistema filosófico, destacase principalmente a "Fenomenologia do espírito", de 1807. Nesta obra, Hegel discute sua teoria sobre a fenomenologia, a essência e a questão da consciência (HEGEL, 1974).

Nessa obra, Hegel expõe sua explicação do espírito, este como uma consciência que se conhece e, a partir deste movimento de conhecimento, parte para compreender a essência do objeto (CHAUÍ, 2000). Para Hegel (1974), 
quando o espírito é representado primeiro como substância do elemento da coisa pura, torna-se a essência eterna, simples e igual a si, não sendo a essência abstrata, mas o espírito absoluto.

A dialética hegeliana, então, toma como base a ideia que o objeto de análise é aquilo que se representa na consciência do sujeito consciente. Hegel não trabalha a dialética como um método ou um modelo, mas a própria realidade e, como tal, é dinâmica (HEGEL, 2018). Para Hegel (1974), toda a realidade é a categoria pura. A razão que se reconhece no objeto encontra expressão no idealismo em que capta razão apenas quando é inicial e fantasia aquilo indicado por uma pura mina de consciência de todo ser. Para Hegel (2018, p. 73), a dialética é o "[...] ir-além imanente, em que a unilateralidade e a limitação das determinações do entendimento se apresentam como aquilo que ela é, a saber como a sua negação. Todo finito é isto: suprimir-se a si mesmo". Para o autor, assim, o movimento dialético forma a alma motriz do progresso científico.

Esse sistema dinâmico da dialética toma o conflito de uma tese e uma antítese, sendo estas condições contraditórias e não contrárias para chegar a uma síntese, que seria uma constatação final deste embate, e esta síntese se tornaria uma nova tese, que sofreria um confronto de uma nova antítese e gerando uma nova síntese, em um modelo espiral, e não cíclica (LIMA, 1994).

Contrário à dialética hegeliana, Marx cria sua dialética sobre a concepção do materialismo. Para Marx (1996), seu método dialético não somente difere de Hegel, como o considera sua antítese. Diferentemente de Hegel, Marx aponta que o conflito entre tese e antítese para formulação da síntese ocorre pelos objetos e não pela consciência. Marx (1996) aponta que na dialética hegeliana, o processo de pensamento que transforma o sujeito em um ser autônomo só ocorre quando externalizado, enquanto a dialética materialista (marxista) considera o ideal aquilo que é material, transposto e traduzido na cabeça do homem. Em outras palavras, enquanto para Hegel o objeto se apresenta na consciência, conforme Marx para a apresentação do objeto na mente do sujeito ele deve se apresentar concretamente (MARX, 1996).

O método de Marx foi discutido por diversos autores. Chagas (2011, p. 57), um desses autores, entende que "o método dialético de Marx não é um instrumento, uma técnica de intervenção externa do pensamento ao objeto, como que um caminho pelo qual o pensamento manipula, a partir de hipóteses exteriores, o objeto". Neste sentido, para o autor, o método dialético de Marx deve considerar o livramento de opiniões pré-concebidas sobre o objeto, considerando apenas o seu movimento. 
O movimento dialético e sua concepção inspiraram Marx a elaborar suas obras, sendo "O capital", de 1867, a de maior destaque, onde Marx amplia sua crítica ao método empirista da economia clássica e a crítica à dialética de Hegel (MARX, 1996).

Diante do exposto, nota-se que o movimento dialético possui diferentes vertentes de análises, considerando os diversos autores e seus posicionamentos. Suas vertentes, desse modo, apontam para diferentes categorias para análises. Sendo assim, a próxima seção visa identificar as principais categorias tomadas para a dialética no campo de estudos de administração: hegeliana e marxista.

\section{DIALÉTICA HEGELIANA E MARXISTA}

Hegel, em toda sua filosofia, possui como principal característica, o movimento ideal, cujos objetos se apresentam na consciência do indivíduo. Para tanto, o filósofo deve compreender a essência do objeto, que é propriedade apenas daquele indivíduo. Para alcançar esta essência, o filósofo deve se despir de todas as concepções mais objetivas e superficiais e obter um pensamento puro, livre de todas as pressuposições e conceitos prévios (HEGEL, 1974). Nesse sentido, a dialética hegeliana é tratada na consciência pensada. Assim, a contradição entre os elementos ocorre em nível abstrato, da consciência.

Para compreender a dialética, é importante entender o movimento da tese, antítese e síntese. A tese, neste ponto, consiste no elemento que se observa, enquanto a antítese seria a contradição deste elemento e que conflitam para gerar uma síntese. A síntese, neste ponto, não é uma simples tese, mas um elemento evoluído, um elemento que superou, extraído deste conflito de teses e antíteses (NASCIMENTO JÚNIOR, 2000).

A antítese não pode ser o contrário da tese, uma vez que o contrário referencia o oposto e, ao confrontar com a tese, compreenderia toda a realidade. Por sua vez, a antítese é o contraditório, é a negação da tese e, como tal, em uma proposição é colocada a preposição não (NASCIMENTO JÚNIOR, 2000; GADAMER, 2012).

Em outras palavras, Chauí (2000) aponta que na verdadeira contradição dialética, os termos contraditórios não são dois positivos contrários ou opostos, mas dois predicados contraditórios do mesmo sujeito e que o negativo não é um positivo contrário a outro positivo, mas verdadeiramente negativo, como árvore e não árvore, onde o primeiro consiste na síntese e o segundo na antítese.

Todo esse conflito, como já mencionado, ocorre na dialética hegeliana, na consciência e os elementos da dialética são os fenômenos que se expressam pela 
essência do objeto na consciência (GADAMER, 2012). Para Hegel (1974, p. 54), "na verdade, o objeto aparenta ser para ela tal como ela o conhece".

Conforme a dialética hegeliana, a consciência possui três estágios, sendo o primeiro estágio quando o indivíduo possui a consciência de si e consegue interpretar os objetos por si mesmo. No segundo estágio o filósofo toma consciência do outro e, neste ponto, sente-se isolado por observar que sua consciência é que dá sentido às coisas. O último estágio considera o espírito absoluto, onde o filósofo, consciente de si e do outro, reconhece seu local no mundo e sua forma de modificar este mundo (HEGEL, 1974). Hegel reconhece em Napoleão o verdadeiro espírito absoluto, uma vez que é um ser que tem consciência de si, do outro e sua força para modificar as relações ao seu redor.

A dialética hegeliana ainda visa ao reconhecimento da consciência, esta descrita na dialética do senhor e do escravo, onde a consciência do senhor dependeria do reconhecimento da consciência do escravo o referindo como o senhor e, só seria um senhor se houvesse esse reconhecimento (GADAMER, 2012).

Neste sentido, o senhor toma-se como um prisioneiro deste processo de reconhecimento, enquanto o escravo estaria livre e em contato com a modificação do mundo. Sobre este ponto, contudo, a concretude dos atos se daria pela consciência às avessas, ou seja, o senhor, embora aprisionado na necessidade de ser reconhecido por um escravo, se via pela observação deste escravo que era livre e assim se sentia superficialmente (GADAMER, 2012).

Da dialética hegeliana nota-se ainda a observação para diferentes áreas das ciências sociais, tais como o direito, o Estado, por exemplo. Partindo para a ideia do Estado, diz Hegel (1974, p. 139): “a representação deste homem verdadeiro reside no Estado que será a forma objetiva, geral, canônica por assim dizer, que reúne e funde os sujeitos individuais apesar das múltiplas diferenças que os separam".

Marx (2005), por sua vez, observava que o Estado não é absoluto e os interesses que o Estado busca são os interesses das classes dominantes. Assim, a visão materialista do Estado é voltada para as relações sociais como entendimento da formação do Estado (MARX, 2005).

A dialética marxista parte da crítica do modelo hegeliano, considerando-o abstrato e pouco útil para a concepção da realidade (MARX, 2011). Conforme Marx (1996), o materialismo dialético parte da determinação do pensamento a partir da própria realidade.

A dialética materialista delimita seu objeto a partir da produção burguesa moderna, onde os indivíduos consistem em membros de conjuntos sociais e, 
como tal, são interligados por relações complexas (CHAGAS, 2011, p. 66). Marx (1996, p. 141) aponta que a configuração racional da dialética "é um incômodo e um horror para a burguesia e para seus porta-vozes doutrinários, porque, no entendimento positivo do existente, ela inclui ao mesmo tempo o entendimento da sua negação, da sua desaparição inevitável”.

Esse incômodo parte da apresentação do conflito do trabalhador (dono da força de trabalho) com o burguês (dono do capital). Segundo Marx (1996, p. 349), enquanto parte da sociedade possua o monopólio dos meios de produção, o trabalhador deverá adicionar "tempo de trabalho necessário à sua autoconservação um tempo de trabalho excedente destinado a produzir os meios de subsistência para o proprietário dos meios de produção". A dialética materialista rejeita o posicionamento do atomismo social, onde o indivíduo singular era visto apenas como um elemento à parte da sociedade. Para a dialética materialista, o indivíduo é um ser que produz (CHAGAS, 2011).

De acordo com Williams (2005), uma abordagem à teoria cultural marxista deve considerar os conceitos de base e de superestruturas. A base, neste conceito, consiste no processo cultural humano, na existência social real, nas relações de produção reais. As superestruturas correspondem às instituições que exercem alguma influência dentro do processo social. Em outras palavras, conforme Denhardt e Catlaw (2017), as bases consistem na força socioeconômica em que a sociedade se mantém, enquanto os fenômenos jurídicos, artísticos, religiosos são reflexos das superestruturas.

Williams (2005) aponta ainda que, devido às dificuldades da proposição de base e superestruturas, surge a ideia da totalidade social, esta considerada como um resultado da produção da sociedade geral, advindo das produções individuais que se interligam e se correlacionam e que estão determinadas. Para o autor, contudo, o conceito de totalidade deve ser associado ao conceito de hegemonia, como forma de evitar possíveis equívocos conceituais, uma vez que a hegemonia supõe a existência de algo verdadeiramente total.

Esta análise sobre as superestruturas e da base, considerando que há grupos dominantes considera, na teoria marxista, o conflito de classes, sendo esta dividida entre os proletariados, aqueles que exercem a atividade laboral, e a burguesa, dominante, que é dona do maquinário e das ferramentas de trabalho. Marx via as mudanças históricas como resultados dos conflitos entre classes econômicas (MARX, 1996; DENHARDT; CATLAW, 2017).

Considerando as ideias de Hegel e Marx sobre a dialética, embora conflituosas, é possível observar que tomam sua observação por meio dos conflitos e de posicionamentos contraditórios. Associando às teorias sociais, 
para Denhardt e Catlaw (2017), é sua função expor as aparências do presente para alcançar um futuro, e esta relação ocorre de forma conflituosa, que ocorre por um movimento dialético, e é por meio desta crítica que consegue expandir e superar os processos atuais.

Neste caso, ao buscar os movimentos nas ciências sociais, e na administração como um campo aplicado, observa-se que a dialética se encontra presente de formas diferenciadas e sendo sua análise importante para mostrar condutores de uma possível mudança social.

\section{PROCEDIMENTOS METODOLÓGICOS}

Para se atingir os objetivos propostos neste trabalho como procedimento técnico propôs-se a realização de uma pesquisa bibliográfica, que foi elaborada a partir de material já publicado, portanto fontes secundárias, constituído principalmente de artigos de periódicos que estejam disponíveis nas bases de dados: Portal Spell e periódico Organizações \& Sociedade, em língua portuguesa e que estejam relacionados ao estudo de dialética na administração.

Inicialmente optou-se por pesquisar no portal Spell, para o campo Resumo, utilizando da pesquisa booleana, em que utilizaram as seguintes buscas: (1) dialética + Administração; (2) dialética + Administração pública. A busca no portal Spell filtrou a busca para o período de janeiro de 2014 a maio de 2019. Esse portal foi selecionado considerando o fato de ser um indexador de periódicos brasileiros no campo de administração, sendo um caminho mais direto para a busca dos resultados selecionados.

Além do portal Spell, foi realizada uma busca no periódico Organizações \& Sociedade (O\&S), dos volumes 68 a 81, referente aos anos de 2014 a 2016, mais as duas primeiras edições do ano de 2017, para verificar em seu conteúdo artigos que tenham como temática a dialética. Tal periódico foi escolhido diante da procura por periódicos brasileiros com Qualis Capes " $\mathrm{A}$ ” para Administração Pública e de Empresas, Ciências Contábeis e Turismo e com discussão teórica sobre dialética. Nesse sentido, considerou-se sua relevância para o campo dos estudos de administração, bem como por ter apresentado em 2015 um volume especial sobre marxismo, importante expoente no estudo da dialética.

Os artigos foram categorizados em 4 categorias principais que nortearam a análise: o uso da dialética (epistemologia, metodologia), o debate da dialética, a dialética na administração, a dialética na administração pública. 


\section{O QUE OS TRABALHOS DE ADMINISTRAÇÃO TRAZEM SOBRE DIALÉTICA?}

A pesquisa no portal Spell foi realizada com duas formas booleanas. $\mathrm{Na}$ busca (1), em que foram contemplados os termos Dialética + Administração para o campo de resumo, foram identificados 30 artigos. Em seguida foi realizada a pesquisa (2), contemplando os termos Dialética + Administração pública, que retornou com nenhum artigo.

De forma a ampliar os resultados encontrados, foi feita a busca no periódico Organizações \& Sociedade. Assim, foram extraídos 17 artigos que citavam pelo menos uma vez a palavra dialética ou dialetical, uma vez que o periódico possui publicações em língua inglesa. Ao iniciar a análise dos artigos, notou-se que 2 artigos encontrados no periódico Organizações \& Sociedade estiveram presentes nos encontrados pela busca no Spell. Assim, após eliminar os artigos duplicados, foram analisados 45 artigos.

Alguns trabalhos abordam a dialética como um método complementar para a realização de pesquisas sociais qualitativas, outros a abordam na forma da construção dos argumentos da problematização pesquisada, demonstrando um movimento entre pressupostos contraditórios inerentes a determinada realidade social, expondo possíveis mudanças sociais e superação da alienação do trabalhador. Foram encontradas manifestações da dialética como um método de pesquisa social, como perspectiva epistemológica, como contradição, oposição, mudança social e histórica.

A dialética como método de pesquisa social, é abordada por Godoi, Coelho e Serrano (2014), que a concebem como uma das três perspectivas para construção da pesquisa social, considerando que a investigação social deve ser abordada de modo complementar, retratando "como se faz, porque se faz e para quem se faz" a pesquisa social, sendo a perspectiva dialética direcionada para quem a pesquisa é realizada.

Na concepção de Ibáñez (2010), é classificada como contendo influências marxistas e psicanalíticas, a investigação dos fenômenos sociais se dá como um movimento dialético, em que ao se pesquisar a ordem social, o pesquisador a transforma e se transforma a si próprio, ou seja, a análise transforma o que está fechado e coberto em aberto, colocando em manifesto o latente. Para o autor, só foi possível a realização de pesquisa social com enfoque em uma perspectiva dialética voltada para a compreensão do nível epistemológico da pesquisa - sendo esta uma das três perspectivas consideradas pelo autor, ao 
lado, da perspectiva distributiva (empirista, nível tecnológico) e estrutural (nível metodológico) - a partir de uma dupla ruptura nas ciências sociais: estatística e linguística (IBÁÑEZ, 2010).

A integração das três perspectivas epistemológicas, supracitadas (distributiva, estrutural e dialética) só é obtida necessariamente a partir das três dimensões que a realidade social conjuga em si mesma: elementos (indivíduos); estruturas (relações invariantes); e sistemas (estrutura aberta, em mudança). Nenhuma delas é autossuficiente, mas se complementam (IBÁÑEZ, 2010; GODOI; COELHO; SERRANO, 2014).

A Análise Sociológica do Discurso (ASD), vinculada à Tradição Espanhola de Pesquisa Social Qualitativa, não é mencionada nos conhecidos manuais de métodos qualitativos e de análise do discurso, mas representa um dos métodos que pode trazer esta complementaridade à pesquisa social. Segundo Alonso (1998), essa abordagem visa destacar o indivíduo como um ator social por meio daquilo que apresenta em seus discursos, considerando como elementos os emissores, os receptores e os meios intersubjetivos que se fazem presentes.

A perspectiva dialética para a pesquisa social é utilizada por Viana, Costa e Brito (2016) para explicar a formação, geração e evolução do conhecimento em marketing sob a luz da hermenêutica crítica. Sob esta ótica, segundo os autores, a epistemologia da hermenêutica é baseada na dialética da explicação e compreensão, em que a compreensão só ocorre com a apropriação da explicação, em uma gama de significações e com o papel ativo daqueles que compreendem. A explicação, por sua vez, ao se tornar independente do agente explicador, passa a ser um objeto de diversas formas de interpretação (PEGINO, 2009).

Nesse contexto, a abordagem crítica da hermenêutica contribui para explicar pontos centrais dos estudos críticos em marketing, como o de que há condições de reconhecer diversos interesses e resistências que se colocam naquele campo determinado de interações, estabelecendo novas possibilidades para sua ressignificação e reconstrução (VIANA; COSTA; BRITO, 2016).

Dalmoro e Nique (2016) também adotam uma perspectiva dialética para a análise dos fluxos globais e das estratégias de preservação local frente às influências externas, considerando neste movimento a compreensão de como a cultura gaúcha em relação à cultura global vem ao encontro de uma série de questões dicotômicas recorrentes da história do estado do Rio Grande do Sul em relação ao resto do mundo.

E este contexto histórico é destacado pelos autores, nesta relação mercado local (locais de consumo tradicionalíssimo gaúcho) mercado global (locais externos ao Rio Grande do Sul), como superestrutura as influências 
simbólicas do passado pastoril gaúcho, que, na concepção dos autores, consiste em uma relação desigual de classes, especialmente na exploração dos patrões sobre os peões.

Após as análises, observa-se, como resultado da interação global-local, a construção de uma relação híbrida e de conflitos entre os diferentes fluxos, em que o mercado demonstrou ser um local alternativo para a disseminação de contrafluxos em resposta aos fluxos globais, visando à preservação da cultura local (DALMORO; NIQUE, 2016). Mas, considerando as limitações encontradas no movimento dialético analisado, os autores destacam:

que a perspectiva de construir uma relação dialética entre o global e o local acabou centrada principalmente na dinâmica do local em relação ao global, uma vez que não foi possível dar voz aos agentes promulgadores dos fluxos globais. Dessa forma, os discursos emitidos pelos agentes globais não foram tratados no âmbito deste estudo. A incorporação de novas vozes na compreensão da dialética global-local pode ser buscada em novos estudos, visando superar essa limitação. Isso permite constatar a maneira como outros agentes se portam frente às ações dos agentes locais, e até mesmo como reestruturam seus discursos para tirar proveito dos fluxos locais (DALMORO; NIQUE, 2016, p. 228).

Oliveira et al. (2018) discutem a dialética como uma epistemologia de análise, utilizando para a análise do objeto, ocorrendo no momento em que há a aproximação do objeto pelo pensamento como conhecimento científico a partir de aproximações dialéticas entre o objeto e o sujeito, passando da totalidade estruturada para a totalidade em movimento. Essa abordagem foi utilizada para analisar os efeitos das moedas sociais em comunidades com baixo desenvolvimento socioeconômico.

Zandonade e Bianco (2014) não retratam explicitamente os conceitos buscados nesta pesquisa, porém trazem uma problematização na área industrial discutindo o trabalho como fundante da práxis social, aspectos da sua posição no sistema capitalista de produção e sua relação com a noção de competências. Desta forma, esperavam identificar se neste contexto específico (uma indústria de alimentos com produção taylorista/fordista), havia valorização dos saberes do trabalhador e se o trabalho pertencia a ele ou ao gestor da empresa.

Nesta concepção do trabalho abordada pelos autores, utilizaram as noções materialistas para análise deste relacionamento trabalhador x trabalho $\mathrm{x}$ sistema de gestão por competências x consciência/conhecimento do trabalho, evidenciando o movimento dialético entre o discurso empresarial de adoção deste sistema de gestão como uma política de valorização do funcionário, mas que na prática demonstrava variadas formas de aplicação que não expressaram 
essa intenção. Fato creditado à natureza específica do trabalho realizado por essa empresa analisada, cuja produção e cujos setores de apoio estão imersos numa linha de produção taylorista/fordista e ao fato de o sistema de gestão adotado incorporar incompletamente os elementos da noção das competências.

A concepção das competências como uma construção social só é possível em organizações realmente horizontalizadas, onde o trabalho abstrato tende a se esvaziar, ou seja, onde há possibilidade do trabalhador da ponta participar da concepção do seu trabalho. Em outras palavras, onde se ameniza a divisão do trabalho, permitindo que todos compreendam o todo e possam decidir sobre sua própria atividade. Nesse ambiente, as relações hierárquicas do trabalho têm uma conotação de aproximar a execução da concepção e do comando (ZANDONADE; BIANCO, 2014, p. 462).

Assim, este processo de entrega derivada da gestão das competências pode produzir um engajamento individual que, mesmo superando a fragmentação, afasta ainda o trabalhador de uma percepção de autor coletivo e de ser pertencente a uma classe social. Pode-se afirmar que enseja um trabalho menos alienado no processo e mais abstrato na relação social (ZANDONADE; BIANCO, 2014).

Também considerando as abordagens sobre relações produtivas, sob diferentes aspectos no campo da administração, Meira (2014) dá foco à maneira em que um grupo de trabalhadores recria vínculos, interações sociais e práticas administrativas herdadas, permitindo uma "mudança social" ao transformar uma Empresa Administrada por Trabalhadores (EAT) constituída como cooperativa de trabalhadores, numa empresa de capital fechado e organizada hierarquicamente, o que o autor atribui à criação da "figura" de um gestor coletivo.

Benini e Benini (2015) abordam a ambiguidade do cooperativismo e da intervenção do Estado inseridos no movimento da economia solidária, questionando a qualidade da solidariedade e os possíveis desdobramentos em termos de reprodução ou criação de uma nova sociabilidade. Apontam que a economia solidária é uma forma alternativa para a crise do trabalho assalariado, já que pode conciliar as necessidades individuais com a necessidade histórica de superação da alienação, permitindo a constituição de uma nova forma de solidariedade sistêmica e com autogestão.

Franco, Sigahi e Saltorato (2018) partem para uma discussão da dialética como a dialética autonomia-subordinação como forma de entender o processo de instituições cooperativas e a relação entre os trabalhadores autônomos em suas atividades, mas subordinados à estrutura das organizações de cooperativas. Para Salgado, Aires e Santos (2018), a dialética foi retratada como uma relação entre o prazer e o sofrimento no trabalho. 
A dialética também foi retratada em estudos voltados para a administração pública, como Rivera e Brito (2015) que recorrem ao conceito de habitus de Pierre Bourdieu, ao analisar as pesquisas em ciências agrárias de uma organização pública, para situar a prática de seus agentes dentro de uma perspectiva histórica de experiências acumuladas pela trajetória coletiva e individual, que a conforma em uma relação dialética entre a agência do indivíduo e a estrutura social do campo.

Os autores verificam "uma grande influência de outros campos no ordenamento da prática e uma hierarquia de capitais calcada principalmente no acúmulo de redes sociais, recursos burocráticos (cargos), financeiros e científicos" (RIVERA; BRITO, 2015, p. 578).

Gamara e Porto (2015) buscam discutir as contribuições teóricometodológicas da Ciência Pós-Normal para a regulação na área de saúde pública, pois consideram que esta abordagem aprofunda e propõe estratégias de gestão de temas complexos relacionados à interface ciência-política, destacando aspectos que a ciência tradicional tende a desconsiderar como as incertezas, o peso dos valores e a pluralidade de perspectivas legítimas.

E nesse movimento dialético que é o processo de regulação da saúde no Brasil, é preciso lembrar que este é um processo de natureza política e econômica, influenciado por uma variedade de interesses, que podem envolver estratégias de coerção e legitimação. Assim:

a articulação entre epistemologia e política, ou entre os diferentes tipos e empregos de conhecimento científico e a qualidade dos processos decisórios, pode ser considerada estratégica para a regulação em saúde. $\mathrm{Na}$ proposta da Ciência Pós-Normal, isso pode ser alcançado através do reconhecimento da complexidade inerente às situações de saúde, bem como pelo destaque dado às incertezas do conhecimento científico e à existência da pluralidade de perspectivas legítimas. Também é necessário a incorporação de uma comunidade ampliada de pares e de metodologias participativas como o checklist de Avaliação da Qualidade do Conhecimento, com o objetivo de tornar as políticas regulatórias e as tomadas de decisão mais qualificadas e democrática (GAMARA; PORTO, 2015, p. 417).

Portanto, no entendimento dos autores a incorporação das estratégias metodológicas da Ciência Pós-Normal pode contribuir para a atividade regulatória em saúde por integrar epistemologia e política, ampliando a qualidade das decisões regulatórias, incluindo de fato a participação social.

Vieira e Gomes (2014), ao analisar as mudanças institucionais, abordam a dialética como uma condição dinâmica da realidade. Para eles as instituições são 
entidades que, embora se trabalha no presente, seu contexto histórico é relevante e suas mudanças com o tempo são constantes, o que considera uma relação dialética entre agentes e estruturas, cujas interações repetidas geram condições diferentes das originais (VIEIRA; GOMES, 2014, p. 684).

Em seu estudo, Vieira e Gomes (2014) discutem sobre a força dos stakeholders nas mudanças sociais, em especial nas políticas públicas. Essa situação destaca a influência que atores sociais desempenham para mudanças sociais e seus impactos na sociedade.

Azevêdo e Grave (2014) trabalham o conceito de administração, considerando que há aplicações equivocadas do termo. Ao tratar o contexto dialético, consideram três perspectivas, a da oposição, onde o termo administração é observado como uma tensão dos opostos revelados pela gestão, política e de liderança; pela perspectiva da correspondência, cuja relação entre os elementos da administração ocorre de forma simétrica; e a perspectiva da complementariedade.

Ferraz (2015) aborda a dialética como um componente para explicação da luta de classe, considerando o conflito interno de uma totalidade, onde o capital e o trabalho se conflitam para gerar melhorias sociais e o Estado deveria se integrar como um componente mediador entre esse conflito.

Tenório (2016), ao relatar a questão do estudo da administração, aborda a dialética do senhor e do escravo, metáfora realizada por Hegel, como uma forma de observar como o curso da Administração no Brasil encontra-se com a visão para a abordagem empírica, criando técnicos ao invés de pensadores.

Nesse contexto, Tenório (2016), embora use um modelo hegeliano para tratar a dialética do estudo da administração, retrata esta abordagem por um modelo materialista, voltada para a concepção marxista de dialética. Para o autor, o curso de Administração é, atualmente, retratado para atender o mercado e não à justiça social (TENÓRIO, 2016). Como síntese, o autor aponta para a necessidade de uma adequação do conteúdo do ensino da administração de forma a retratar o conhecimento prático e teórico para o avanço da ciência administrativa.

Em 2015, o periódico Organizações \& Sociedade realizou uma edição especial voltada para a expansão dos estudos marxistas. Como tal viés, é possível notar que tais estudos apresentam a dialética materialista como condição para a compreensão da realidade.

Partindo do viés materialista, Gurgel e Justen (2015) tratam a dialética como um movimento histórico e, para compreender a realidade, toma-se a concepção da totalidade e do contraditório movimentando a história, conceitos que Marx encontra em Hegel. 
Lacerda (2015) utiliza duas abordagens dialéticas em sua discussão. A primeira, empregada em sua discussão, consiste na abordagem materialista da contradição, onde se apresenta a dicotomia tempo e espaço. Outra abordagem consiste na de Giddens, apontando que as disposições das práticas sociais são colocadas no espaço tempo, cuja relação dialética é não temporal, mas virtualmente dependente de outras práticas.

Os estudos de Chagas, Carvalho e Marquesan (2015), Helal (2015) e Martins e Honório (2014), embora apresentassem contextos para uma possível análise dialética, tal terminologia não foi trabalhada no texto, mas mencionada apenas para contextualizar outros conceitos, funcionando como um adjetivo. Nesses estudos, o termo dialética e suas variações foi retratado apenas 1 (uma) vez em cada estudo, cujo termo não apresentou descrição e desenvolvimento para compor uma análise dialética.

Diante dos estudos analisados, nota-se que todos tiveram abordagem materialista para o tratamento dialético. Essa concepção marxista pode ser relacionada pelo conteúdo expresso nesses estudos, cujo tema de estudo tem como viés a materialidade e o conflito de objetos, de difícil concepção no plano das ideias, como proposto por Hegel. Essa predominância da abordagem materialista da dialética pode ser fruto da expansão marxista e da ruptura paradigmática, permitindo que as ciências sociais busquem a compreensão da realidade a partir do construtivismo, cuja realidade é construída por meio das relações sociais.

Também se observa que dos 17 artigos considerados neste relato, apenas dois abordam problematizações relacionadas diretamente à administração pública, um direcionado para regulação da saúde pública e outro para o entendimento das práticas institucionais nas pesquisas agrárias.

\section{QUAIS AS PERSPECTIVAS E REFLEXÕES ENCONTRADAS NOS TRABALHOS ACADÊMICOS PARA A ADMINISTRAÇÃO PÚBLICA?}

Os artigos analisados neste estudo abrangeram áreas direcionadas ao desenvolvimento teórico, metodológico e empírico no campo da administração, destacando temas como métodos qualitativos de pesquisa social, práticas gerenciais, normatização e relações sociais.

Considerando a perspectiva metodológica independente que foi apresentada, com referência à ASD, que ainda carece de consolidação numa escola propriamente dita, pode-se vislumbrar uma lacuna quanto ao seu enquadramento dentro das pesquisas sociais qualitativas. Segundo Godoi, Coelho e Serrano (2014), 
a ASD, por ser movida por múltiplas influências linguísticas e sociológicas, ainda não possui um lugar específico, pairando sobre uma indefinição considerável de identidade e de delimitação de espaço.

Por ser pouco difundida, é preciso se atentar para as pseudoanálises em ASD. Estas não caracterizam apenas a ASD, mas a maioria das formas de análise do discurso ou pesquisa qualitativa - âmbitos em que também costumam ser frequentes. As principais pseudoanálises podem ser: "através de síntese, baseada na tomada de posição; por excesso ou isolamento de citações, circular dos discursos e dos construtos mentais, por falsa generalização; ou por localização dos elementos" (GODOI; COELHO; SERRANO, 2014, p. 528).

Portanto, além dos cuidados ao se realizar uma ASD também há um gap na área dos estudos de discurso nos estudos organizacionais, que promova o intercâmbio com as discussões do campo da sociologia, permitindo encontrar uma metodologia que contemple o discurso (ALONSO, 1998), principalmente, voltado para a pesquisa social em administração pública.

Outra área a ser considerada é a de marketing. Conforme ressaltam Viana, Costa e Brito (2016), os estudos críticos em marketing permitiram a eles concluir que é necessário o desenvolvimento de consciência política entre os profissionais e os teóricos desta área, fazendo com que a prática de marketing não seja alienada nem alienante.

Considerando o campo da administração pública em que na maioria das vezes o marketing é utilizado para promoção dos interesses pessoais do gestor ou um grupo dominante, seria importante a realização de abordagens críticas nessa área, já que das funções administrativas, esta é uma das que mais interage e influencia a percepção da sociedade.

É no Setor Público que se concentra grande parte da força de trabalho local: os servidores públicos municipal, estadual ou federal. Portanto, estudos voltados para a compreensão dos conflitos nas relações entre servidor público e gestor da administração pública serão relevantes para subsidiar políticas públicas de gestão de competências para os recursos humanos, que busquem a valorização do servidor em seu meio.

Considerando o jogo político que se dá na gestão pública, seria possível ao servidor público ser o dono do seu trabalho? Segundo Zandonade e Bianco (2014), uma possível volta do trabalho ao trabalhador, deve-se considerar a noção de competências que viabiliza a construção do próprio indivíduo no trabalho ao mesmo tempo em que o realiza (teleologia), ou seja, por meio do desenvolvimento de competências e sua aplicação em relação ao seu meio social. Pois para os autores um sistema de gestão de competências pode em algum grau modificar a relação 
trabalhador versus trabalho, trazendo uma possível construção social do trabalho em que o indivíduo possa voltar a ter noção de todo o processo de concepção, não se restringindo apenas a divisão automática do trabalho, alcançando algum nível de conhecimento do próprio trabalho, passando a ser o "seu dono".

Esta abordagem representa uma lacuna dos estudos organizacionais sobre o trabalho que envolvam o uso da noção de competências, principalmente no Brasil. Logo, entende-se que possa ser aplicada esta análise no campo da administração pública.

$\mathrm{Na}$ formação do gestor público, Assis e Paula (2014) discutem sobre a semiformação e a formação do gestor público, colocando em pauta o papel da gestão social como elemento para promover melhorias na gestão pública.

No campo da gestão de pessoas da administração burocrática, podemse realizar algumas investigações buscando entender como é percebida pelo servidor público a sua relação com o trabalho, podendo contribuir para o estudo de modelos de gestão de competências aplicáveis na administração pública trazendo valorização do servidor com sua aceitação da sociedade.

É possível ainda observar a discussão da força social como um meio de mudança no meio social. Vieira e Gomes (2014) apontaram para a necessidade da análise de stakeholder como influenciador da formulação e implementação de políticas públicas, enquanto Ferraz (2015) aponta para a consciência da classe trabalhadora para realizar as mudanças sociais necessárias para a classe, enquanto o Estado tem o papel de formular políticas públicas para intermediar este conflito.

Sobre a construção social do trabalho e das relações de produção, identifica-se nos trabalhos de Meira (2014) e Benini e Benini (2015) o gestor coletivo e a economia solidária, como exemplos de possibilidades de superação da alienação e ao mesmo tempo alternativas à crise do desemprego não equacionada pelo Estado, enquanto agente mantenedor da ordem social e provedor de bens e serviços públicos.

O debate sobre políticas públicas não é recente, mas compreender suas dimensões políticas e filosóficas, que não apenas no Brasil, predominantemente estão direcionadas para o crescimento econômico defendido como "a solução para todos os problemas" é relevante para a construção de políticas que realmente permitam a integração da população.

Desse modo, é importante trazer para a arena do desenvolvimento das políticas públicas brasileiras, outras abordagens teóricas que possam contribuir para um pensar diferenciado na garantia de direitos fundamentais, seja na área da saúde pública ou qualquer outra área social, envolvendo a interação entre vários campos institucionais pode resultar em políticas "mais maduras", com maior qualidade e que de fato possam minimizar alguns problemas sociais. 


\section{CONSIDERAÇÕES FINAIS}

O presente estudo identificou poucos estudos que utilizaram da dialética para discussão da administração pública, muito devido à perspectiva predominante do positivismo. Ainda assim, entre os identificados que utilizaram da dialética como epistemologia ou metodologia, percebe-se a predominância da abordagem materialista nos trabalhos acadêmicos analisados no período de 2014 a 2017 na revista Organizações \& Sociedade, o que leva à inferência de que, na visão destes autores, o corpo e a mente são indissociáveis e os seres humanos podem modificar o mundo real, e não somente observá-lo, postura contrária à visão idealista hegeliana de que o mundo real é reflexo do mundo ideal.

A abordagem materialista surge da visão de Marx, cujas correntes brasileiras de discussão dialética alimentam da vertente marxista, sendo principal motivo dessa predominância dentro dos estudos brasileiros.

Em alguns casos, identifica-se o estudo das formas de produção da vida material da sociedade (materialismo histórico), influência creditada à vertente marxista em que se afirma que as relações sociais são fruto do trabalho dos seres humanos, bem como do que produzem para suprir suas necessidades materiais.

Os estudos analisados adotam uma postura de construção da ciência a partir da ruptura do domínio de métodos tradicionais com a incorporação de métodos com perspectivas diferenciadas para se compreender e explicar a realidade: como a dialética.

Mais precisamente, nota-se que a dialética nestes trabalhos, embora tendo o modelo materialista de Marx como base, possui diferentes formas de abordagem e de conceituação, podendo ser retratada como conflito, como movimento e como análise histórica. Apesar de esses termos terem a mesma origem dialética (a relação entre tese e antítese), o fato de se apresentarem de forma distinta nos textos pode ser uma constatação de que a dialética é, assim como apontada, a própria realidade.

\section{REFERÊNCIAS}

ABBAGNANO, N. Dicionário de filosofia. São Paulo: Martins Fontes, 2007. ALONSO, L. E. La mirada cualitativa en sociología. Madrid: Fundamentos, 1998.

ASSIS, L. B.; PAULA, A. P. P. Gestão Sociale Bildung: reflexões sobre a importância da formação para a democratização no setor público. Administração Pública e Gestão Social, Viçosa, v. 6, n. 2, p. 57-64, 2014. 
AZEVÊDO, A.; GRAVE, P. S. Prolegômenos a toda a administrologia possível: administração - o que é isto? Organizações \& Sociedade, Salvador, v. 21, n. 71, out./dez. 2014. p. 695-712.

BENINI, É. A.; BENINI, E. G. A construção do trabalho associado sob a hegemonia estatal: organização, solidariedade e sociabilidade. Organizações \& Sociedade, Salvador, v. 22, n. 74, p. 325-344, jul./set. 2015.

CHAGAS, E. F. O método dialético de Marx: investigação e exposição crítica do objeto. Síntese: Revista de Filosofia, Belo Horizonte, v. 38, n. 120, p. 55-70, 2011. CHAGAS, P. B.; CARVALHO, C. A.; MARQUESAN, F. F. S. Desenvolvimento e dependência no Brasil nas contradições do Programa de Aceleração do Crescimento. Organizações \& Sociedade, Salvador, v. 22, n. 73, p. 269-289, abr./jun. 2015.

CHAUÍ, M. Convite à filosofia. São Paulo: Ática, 2000.

DALMORO, M.; NIQUE, W. M. Fluxos e contrafluxos: a relação global e local mediada pelo mercado na cultura gaúcha. Organizações \& Sociedade, Salvador, v. 23, n. n. 77, p. 211-230, abr./jun. 2016.

DENHARDT, R. B.; CATLAW, T. J. Teorias da administração pública. $2^{\mathrm{a}}$. ed. São Paulo: Cengage Learning, 2017.

FERRAZ, D. L. D. S. Projetos de geração de trabalho e renda e a consciência de classe dos desempregados. Organizações \& Sociedade, Salvador, v. 22, n. 72, p. 123-142, jan./mar. 2015.

FRANCO, G. M.; SIGAHI, T. F. A. C.; SALTORATO, P. Autogestão, politecnia e organização do trabalho: um estudo etnográfico em uma cooperativa de reciclagem de Sorocaba/SP. Revista de Gestão Social e Ambiental, Recife, v. 12, n. 3, p. 2-20, 2018.

GADAMER, H-G. Hegel - Husserl - Heidegger. Petrópolis, RJ: Vozes, 2012. GAMARRA, T. P. D. N.; PORTO, M. F. D. S. Regulação em saúde e epistemologia política: contribuições da Ciência Pós-Normal para enfrentar as incertezas. Organizações \& Sociedade, Salvador, v. 22, n. 74, p. 405-422, jul./set. 2015.

GIANNOTTI, J. A. Dialética x analítica. Analytica, Rio de Janeiro, v. 12, n. 2, p. 35-45, 2008.

GODOI, C. K.; COELHO, A. L. D. A. L.; SERRANO, A. Elementos epistemológicos e metodológicos da análise sociológica do discurso: abrindo possibilidades para os estudos organizacionais. Organizações \& Sociedade, Salvador, v. 21, n. 70, p. 509-536, jul./set. 2014. 
GURGEL, C.; JUSTEN, A. Teorias organizacionais e materialismo histórico. Organizações \& Sociedade, Salvador, v. 22, n. 73, p. 199-221, abr./jun. 2015. HEGEL, G. W. F. A Fenomenologia do espírito. São Paulo: Abril Sa. Cultural e Industrial, 1974.

HEGEL, G. W. F. Ciência da lógica: 1 doutrina do ser. Petrópolis: Vozes, 2016.

HEGEL, G. W. F. Enciclopédia das ciências filosóficas em epítome. Lisboa: Edições 70, 2018.

HELAL, D. H. Mérito, reprodução social e estratificação social: apontamentos e contribuições para os estudos organizacionais. Organizações \& Sociedade, Salvador, v. 22, n. 73, p. 251-267, abr./jun. 2015.

IBÁÑEZ, J. Perspectivas de la investigación social: el diseño en las tres perspectivas. In: GARCÍA, M.; IBÁÑEZ, J.; ALVIRA, F. (org.). E1 análisis del realidad social: métodos y técnicas de investigación. Madrid: Alianza Editorial, 2010. p. 42-75.

LACERDA, D. S. Overcoming dichotomies through space: the contribution of dialectical materialism to organization studies. Organizações \& Sociedade, Salvador, v. 22, n. 73, p. 223-235, abr./jun. 2015.

LIMA, C. R. V. C. Carta sobre dialética: o que é dialética? Síntese Nova Fase, Belo Horizonte, v. 21, n. 67, p. 439-447, 1994.

MARTINS, A. A. V.; HONÓRIO, L. C. Prazer e sofrimento docente em uma instituição de ensino superior privada em Minas Gerais. Organizações \& Sociedade, Salvador, v. 21, n. 68, p. 79-96, jan./mar. 2014.

MARX, K. O capital. São Paulo: Editora Nova Cultura, 1996. v. 1.

MARX, K. Crítica à filosofia do direito de Hegel. São Paulo: Boitempo, 2005.

MARX, K.; ENGELS, F. A sagrada família. São Paulo: Boitempo, 2011.

MEIRA, F. B. O gestor coletivo: psicodinâmica grupal em empresas assumidas por trabalhadores. Organizações \& Sociedade, Salvador, v. 21, n. 70, p. 425 442, jul./set. 2014.

NASCIMENTO JÚNIOR, A. F. Fragmentos do pensamento dialético na história da construção das ciências da natureza. Ciência \& Educação, Bauru, v. 6, n. 2, p. 119-139, 2000. 
OLIVEIRA, E. G.; BENINI, E. G.; ESTIVAL, K. S. G.; NEMIROVSKY, G. G.; NASCIMENTO, D. F. Moedas sociais e suas contribuições em comunidades economicamente precarizadas: um estudo exploratório da experiência do Projeto Pet Mania em Campo Grande - MS. Desenvolvimento em Questão, Ijuí, v. 16, n. 43, p. 453-486, 2018. http://dx.doi.org/10.21527/2237-6453.2018.43.453-486. PEGINO, P. M. F. Reflexões sobre as possibilidades teórico-metodológicas da hermenêutica ricoeuriana para o estudo do discurso como objeto dos estudos organizacionais. In: ENCONTRO NACIONAL DA ASSOCIAÇÃO NACIONAL DOS PROGRAMAS DE PÓS-GRADUAÇÃO EM ADMINISTRAÇÃO, 33., 2009, São Paulo. Anais [...]. São Paulo: ANPAD, 2009. p. 1-12.

RIVERA, A. S. P.; BRITO, M. J. D.; A pesquisa como prática social: um estudo sob a perspectiva bourdieusiana. Organizações \& Sociedade, Salvador, v. 22, n. 75, p. 561-582, out./dez. 2015.

SALGADO, C. C. R.; AIRES, R. F. F.; SANTOS, F. J. S. D. Dialética do 'prazer e sofrimento': a relação de mestrandos e doutorandos com seu trabalho acadêmico. Contextus: Revista Contemporânea de Economia e Gestão, Fortaleza, v. 16, n. 2, p. 113-145, 2018. http://dx.doi.org/10.19094/contextus. v16i2.1049.

TENÓRIO, F. G. Administração e a questão social: entre o "robinsonismo" e o "étiennismo". Organizações \& Sociedade, Salvador, v. 23, n. 78, p. 460-486, jul./set. 2016.

VIANA, M. F.; COSTA, A. P.; BRITO, M. J. D. A hermenêutica crítica e estudos em marketing: aproximações e possibilidades. Organizações \& Sociedade, Salvador, v. 23, n. 76, p. 92-109, jan./mar 2016.

VIEIRA, D. M.; GOMES, R. C. Mudança institucional gradual e transformativa: a influência de coalizões de advocacia e grupos de interesses em políticas públicas. Organizações \& Sociedade, Salvador, v. 21, n. 71, p. 679-694, out./dez. 2014.

WILLIAMS, R. Base e superestrutura na teoria cultural marxista. Revista USP, São Paulo, n. 65, p. 210-224, mar./maio 2005.

ZANDONADE, V.; BIANCO, M. D. F. O trabalho abstrato e a noção de competências: discutindo essa inter-relação no contexto do trabalho industrial.

Organizações \& Sociedade, Salvador, v. 21, n. 70, p. 443-466, jul./set. 2014. 